\title{
Study on effective thermal conductivity of zinc sulphide/ poly(methyl methacrylate) nanocomposites
}

\author{
Sonalika Agarwal • Narendra Sahai Saxena • \\ Vipin Kumar
}

Received: 1 August 2014/Accepted: 24 September 2014/Published online: 9 October 2014

(C) The Author(s) 2014. This article is published with open access at Springerlink.com

\begin{abstract}
Zinc sulphide/poly(methyl methacrylate) (ZnS/ PMMA) nanocomposites with different $(0,2,4,6$ and 8) $\mathrm{wt} \%$ of $\mathrm{ZnS}$ nanoparticles have been prepared by solution casting method. The obtained ZnS/PMMA nanocomposites have been characterized through X-ray diffraction (XRD) and transmission electron microscopy (TEM) measurements. Transient plane source (TPS) technique was used to determine the effective thermal conductivity of ZnS/PMMA nanocomposites over the temperature range from room $\left(30^{\circ} \mathrm{C}\right)$ to $120^{\circ} \mathrm{C}$. The results indicated that the effective thermal conductivity shows increasing behavior up to glass transition temperature beyond which, it becomes constant due to the straightening of chains and vacant site scattering of phonons, respectively. It is also observed that effective thermal conductivity of $\mathrm{ZnS}$ / PMMA nanocomposites increases with the increase of concentration of $\mathrm{ZnS}$ nanoparticles up to $6 \mathrm{wt} \%$ and decreases at $8 \mathrm{wt} \%$. This increase and decrease of thermal conductivity of these nanocomposites are explained on the basis of their structure.
\end{abstract}

Keywords Poly(methyl methacrylate) $\cdot$ Polymer nanocomposites - Thermal conductivity

S. Agarwal $(\bowtie) \cdot$ V. Kumar

Department of Applied Sciences, Krishna Institute of

Engineering and Technology, Ghaziabad 201206, India

e-mail: sonalika.spsl@gmail.com

S. Agarwal · N. S. Saxena

Semi-conductor and Polymer Science Laboratory, Department of Physics, University of Rajasthan, Jaipur 302055, India

\section{Introduction}

Thermal management is becoming increasingly important in many industries including computer/electronics, automotive, and aerospace. Metals have traditionally been used as the main material in these applications, but have disadvantages compared to polymers and composites such as higher density, greater susceptibility to oxidation and lower design freedom. Thus, developing polymeric materials with high thermal conductivity is of great interest to many industrial sectors (Fokushima et al. 2006). Polymers have many applications and uses but are often limited by their inherent physical properties. Most polymers have very low thermal conductivity. To make the polymer viable for potential devices the thermal conductivity of the polymer should be high. For achieving this, fillers with higher thermal conductivity can be incorporated into polymers to form polymer composites (Wong and Bollampally 1999). Recently many efforts have focused on dispersing onedimensional or two-dimensional micro- or nanostructure fillers into the polymer to improve heat transport through them. The thermal conductivity of composite is controlled by the conductivity of filler and matrix, shape and size of the filler and the concentration of filler.

Among polymers, poly methyl methacrylate (PMMA) is considered a good host material in the polymer composites as it is easily available and presents good environmental stability, possesses light weight and bears low cost. Besides this, it is an important transparent thermoplastic material and is widely used in many applications such as lenses, glazing (particularly in aircraft), light pipes, meter covers, bathroom fittings, skylights, transportation and merchandising (Thangamani et al. 2010; Zhao et al. 2008), etc. Recently various nanoscale fillers, including silica, alumina, zinc oxide, zirconia, carbon nanotubes (CNTs), etc. 
(Wang et al. 2005; Ash et al. 2002; Sun et al. 2007) have been reported to enhance the thermal properties of PMMA such as thermal stability and thermal conductivity. The results indicated that the decrease and increase of thermal properties depend on the type of fillers.

From the literature survey, it is observed that effect of $\mathrm{ZnS}$ nanofiller on thermal properties of PMMA has been studied very scantly because $\mathrm{ZnS}$ has been known as one of the most promising photosensitive material owing to its good optical properties. The nanocomposite of $\mathrm{ZnS}$ can provide the possibility to obtain combinations of functionalities, such as thermally conducting composites with good mechanical properties that are optically clear. Thus the study of thermal transport properties of $\mathrm{ZnS} / \mathrm{PMMA}$ nanocomposites will provide an understanding about the heat transport through the devices (optoelectronic, etc.) and their limiting temperature in use. In view of this, in this paper an effort has been made to determine the effective thermal conductivity of $\mathrm{ZnS}$ filled PMMA at room as well as elevated temperatures for different concentrations of $\mathrm{ZnS}$ nanoparticles.

\section{Materials and methods}

Preparation of polymer nanocomposites

The zinc sulphide $(\mathrm{ZnS})$ nanoparticles have been synthesized by wet chemical precipitation method using thioglycerol as a stabilizing agent as described earlier (Agrawal et al. 2011). The fine powder of $\mathrm{ZnS}$ nanoparticles has been used to prepare $\mathrm{ZnS} / \mathrm{PMMA}$ nanocomposite by solution casting method. In this method, firstly PMMA has been dissolved in tetrahydrofuran (THF) solution by magnetic stirrer for $2 \mathrm{~h}$ and then $\mathrm{ZnS}$ nanoparticles with different $(0$, 2, 4, 6 and 8) wt\% have been dispersed into THF solution containing PMMA. The obtained solutions were agitated by ultrasonicator for $20 \mathrm{~min}$ to get the uniform distribution of $\mathrm{ZnS}$ nanoparticles. These solutions were poured in the Petri-dishes to obtain the ZnS/PMMA nanocomposite films. After 2 days, the nanocomposite films were taken out from the Petri-dishes and dried in vacuum $\left(10^{-2}\right.$ torr) for $6 \mathrm{~h}$ to remove the solvent. The thickness of prepared samples was $\approx 0.12 \mathrm{~mm}$.

\section{Structural characterization}

The X-ray diffraction (XRD) spectra of the nanocomposites have been recorded using Bragg-Brentano geometry on a Panalytical X'pert Pro diffractometer with a $\mathrm{Cu} \mathrm{K} \alpha$ radiation source $(\lambda=1.5406 \AA)$. The $\mathrm{X}$-ray tube was operated at $45 \mathrm{kV}$ and $40 \mathrm{~mA}$.
The transmission electron microscopy (TEM) measurements of nanocomposites have been performed on TECNAI G2 30 U-TWIN system operating at an accelerating voltage of $300 \mathrm{kV}$. The samples for TEM measurement were prepared by dissolving ZnS/PMMA nanocomposite films in THF solvent using ultrasonicator. A drop of prepared solution was placed on the carbon-coated copper grid and solvent removed by evaporation at room temperature. The thickness of the thin layer for TEM measurements should be approximately $80-100 \AA$ A.

Thermal conductivity measurement

The effective thermal conductivities of ZnS/PMMA nanocomposites have been determined using transient plane source (TPS) technique. In this method, the transient plane source element behaves both as heat source and temperature sensor. TPS sensor (Fig. 1) consists of an electrically conducting pattern of thin nickel foil $(10 \mu \mathrm{m})$ in the form of double spiral embedded in an insulating layer made of kapton $(50 \mu \mathrm{m})$. Sensor is sandwiched between the two pieces of the samples having perfectly smooth surface so as to ensure perfect thermal contact. For the measurement of effective thermal conductivity of thin film with thickness of the order of microns, the experiment was performed in two steps. In the first step, sensor is sandwiched between the two pieces of the sample, each one with a plane surface facing the sensor. This arrangement was placed between the two auxiliary metal (stainless steel) pieces as shown in the Fig. 2. Data for the temperature increase over a given time were collected using the software available with the Hot Disk Thermal Constant Analyser TPS (model 2500S). In the second step, the experiment was repeated with the Hot Disk sensor sandwiched between the same two pieces of the metal and data for the temperature increase were again collected taking the same experimental conditions as mentioned above. Employing these two temperature increase, thickness of the film and power delivered to the sample, the effective

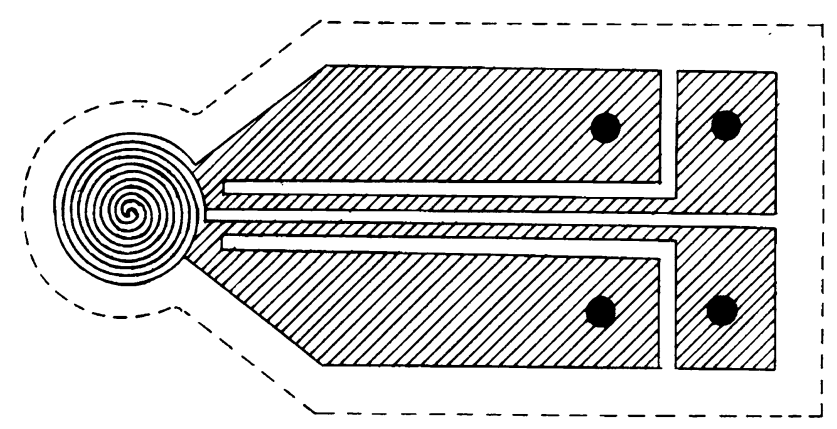

Fig. 1 TPS sensor 


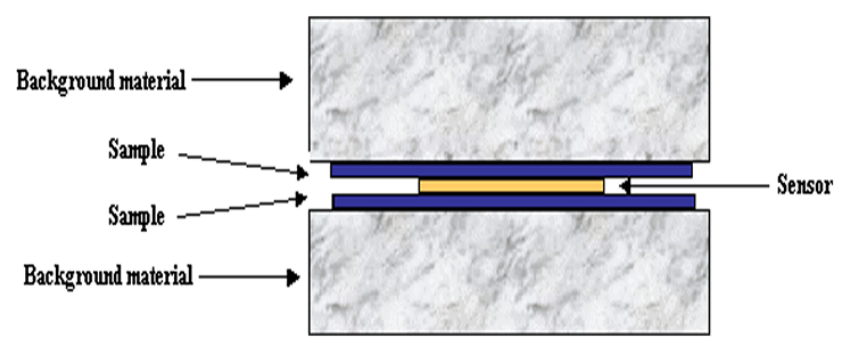

Fig. 2 Illustration of thin film method

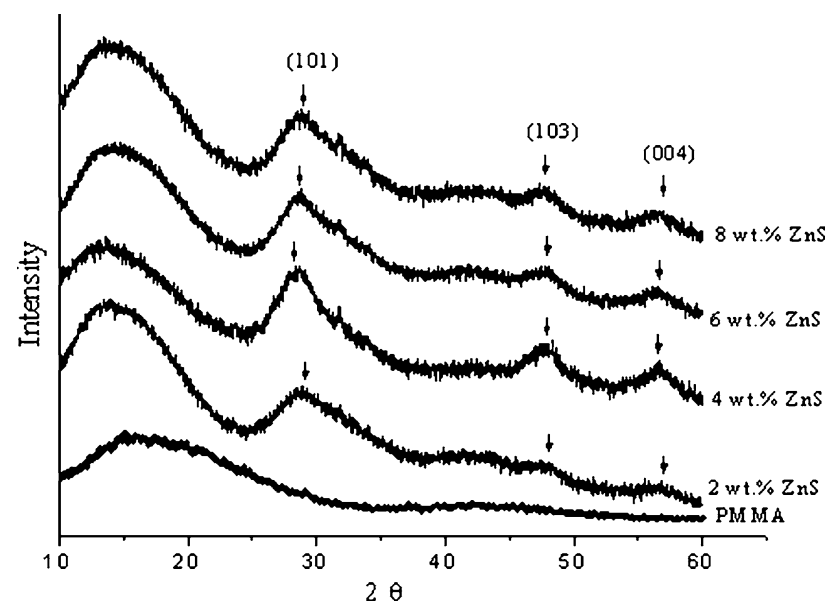

Fig. 3 XRD patterns of PMMA and ZnS/PMMA nanocomposites

thermal conductivity $\left(\lambda_{\mathrm{e}}\right)$ of thin sample can be determined through the following relation:

$\lambda_{\mathrm{e}}=P \Delta x / 2 A \Delta T$

where $P$ is the total output of power given to the sensor, $A$ is the area of conducting pattern of sensor, $\Delta x$ is the thickness of thin samples and $\Delta T$ is the temperature difference across the sample. The factor 2 is due to the symmetrical distribution of heat flux on both sides of the sample. The numbers of specimen taken for the measurement were two and the results of their thermal conductivities have a deviation of about $5 \%$ which is in the range of experimental error of thermal conductivity.

\section{Results and discussion}

Structure and morphology

The XRD patterns of pure PMMA and ZnS/PMMA nanocomposites are shown in Fig. 3. This figure shows one broad hump and three broad peaks in the XRD pattern of the nanocomposites. The first broad hump at lower diffraction angle around $\left(10^{\circ}-20^{\circ}\right)$, confirms the amorphous nature of PMMA. The other three peaks at angles $28.8^{\circ}, 47.8^{\circ}$ and $56.6^{\circ}$ corresponding to (101), (103) and (004) planes, respectively, indicate the hexagonal phase of $\mathrm{ZnS}$ nanoparticles (Agrawal et al. 2011). The XRD peaks are relatively broad due to the small crystalline domains in the materials.

Figure $4 \mathrm{a}-\mathrm{d}$ shows the TEM micrographs of $\mathrm{ZnS} /$ PMMA nanocomposites for 2, 4, 6 and $8 \mathrm{wt} \%$ of $\mathrm{ZnS}$ nanoparticles, respectively. The average particle size of $\mathrm{ZnS}$ nanoparticles is approximately $5 \mathrm{~nm}$. The TEM images for 2 and $4 \mathrm{wt} \%$ of $\mathrm{ZnS}$ nanoparticles indicate that the particles are well dispersed in PMMA whereas small agglomeration is found for $6 \mathrm{wt} \%$ and the agglomeration is enhanced for $8 \mathrm{wt} \%$ of $\mathrm{ZnS}$ nanoparticles. This indicates that particle-particle interaction dominates over the particle-polymer interaction.

\section{Effective thermal conductivity}

The study of thermal properties like thermal conductivity is important to any potential technological application as the environmental and thermal stability of a material should be well characterized to identify the optimal condition for performance of a device. Thermal conductivity $(\lambda)$ is the measure of the ability of a material to transfer heat. The mechanism of heat transport and hence thermal conductivity depends on the structure of the material. In metals, the heat is transferred via free electrons whereas in non-metallic materials, such as polymers, the heat is conducted by phonons or the lattice waves produced by vibrational energy of the atoms (Godovsky 1992; Hands 1999). For a two-phase system like polymer/filler composite, interfacial physical contact (Davis and Artz 1995; Garrett and Rasenberg 19741) between polymer and filler is very critical, since phonons play important role in deciding the thermal conductivity through their mean free paths. The temperature dependence of effective thermal conductivity of pure PMMA and $\mathrm{ZnS} /$ PMMA nanocomposites is shown in Fig. 5.

Results on thermal properties showed that effective thermal conductivity of nanocomposites is higher than pure material. Thus adding $\mathrm{ZnS}$ nanoparticles in PMMA has synergistic effect on the thermal properties (thermal conductivity). It is observed from Fig. 5 that the thermal conductivity of pure PMMA at room $\left(30^{\circ} \mathrm{C}\right)$ temperature is $0.112 \mathrm{~W} / \mathrm{mK}$ and increases with increase in temperature up to glass transition temperature and beyond this temperature it becomes constant. The variation of glass transition temperature $\left(T_{\mathrm{g}}\right)$ with $\mathrm{ZnS}$ concentration in PMMA matrix is shown in Fig. 6. Near glass transition temperature $\left(82{ }^{\circ} \mathrm{C}\right)$ the observed value is $0.18 \mathrm{~W} / \mathrm{mK}$. A similar behavior is observed for all the ZnS/PMMA nanocomposites. The thermal conductivities of ZnS/PMMA nanocomposites with 2, 4, 6 and $8 \mathrm{wt} \% \mathrm{ZnS}$ nanoparticles at $30{ }^{\circ} \mathrm{C}$ are $0.171,0.183,0.211$ and $0.194 \mathrm{~W} / \mathrm{mK}$.

The observed variation in thermal conductivity of PMMA and ZnS/PMMA nanocomposites with temperature 
Fig. 4 TEM micrographs of $\mathrm{ZnS} /$ PMMA nanocomposites a $2 \mathrm{wt} \%$, b $4 \mathrm{wt} \%$, c $6 \mathrm{wt} \%$ and $\mathbf{d} 8 \mathrm{wt} \%$
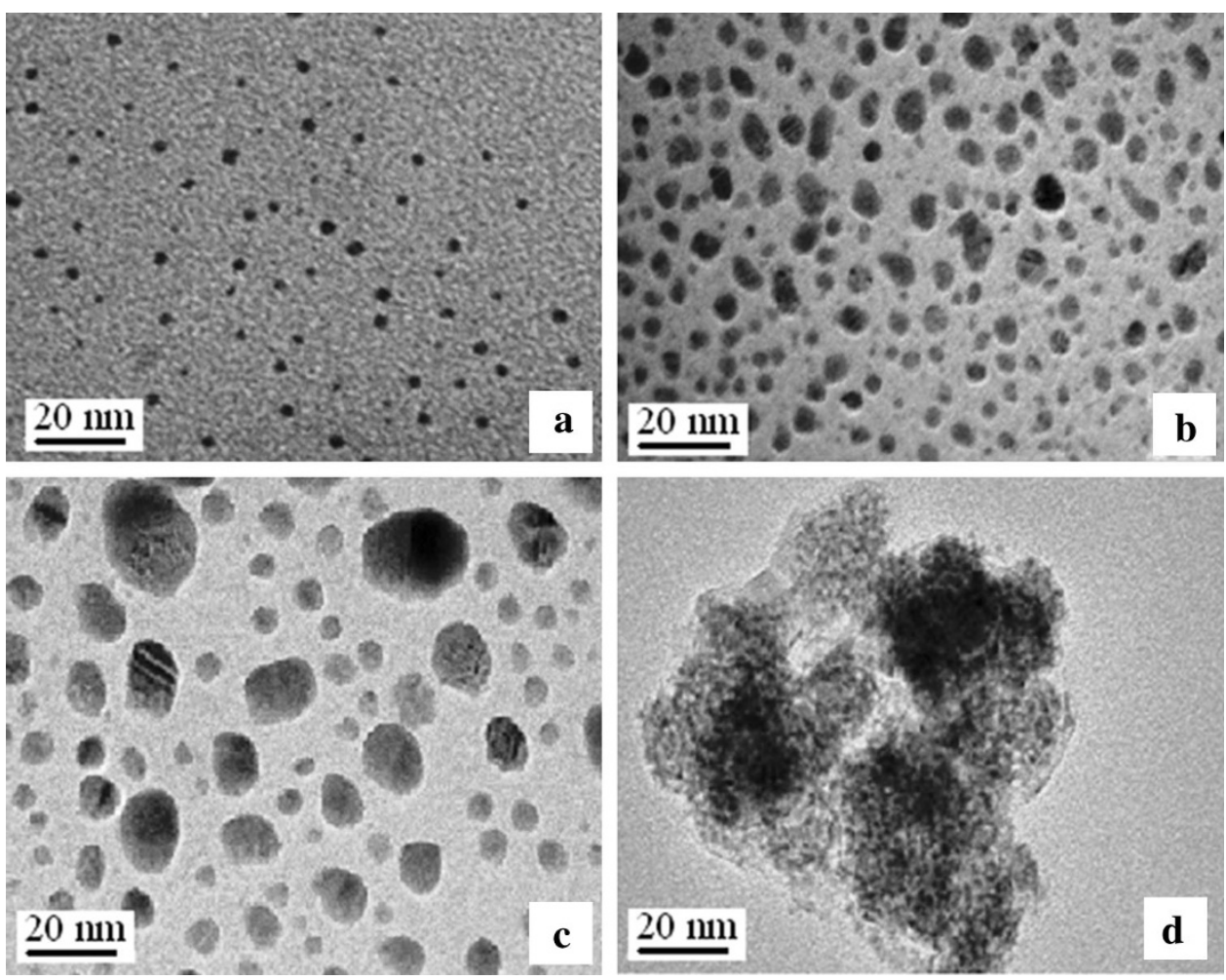

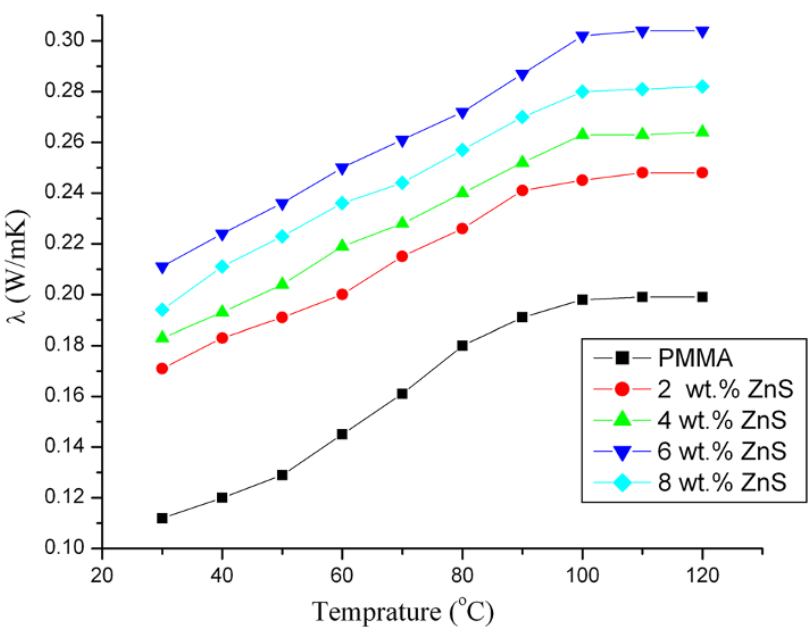

Fig. 5 Temperature dependence of effective thermal conductivity for ZnS/PMMA nanocomposites

is similar as observed (Agrawal et al. 2013) and also can be explained on the basis of various phonon scattering mechanisms such as chain defect scattering, structure scattering and vacant site scattering. The chain defects such as, bends in chains, gaps between two chains in line, chains of smaller lengths, etc. are created in the system during the polymerization of PMMA. Therefore, in the temperature region below $T_{\mathrm{g}}$, the temperature dependence of thermal conductivity is controlled (Perpechoko 1981; Saxena et al. 1999) by the variation of phonon mean free path. As the temperature increases from room temperature up to $T_{\mathrm{g}}$, the

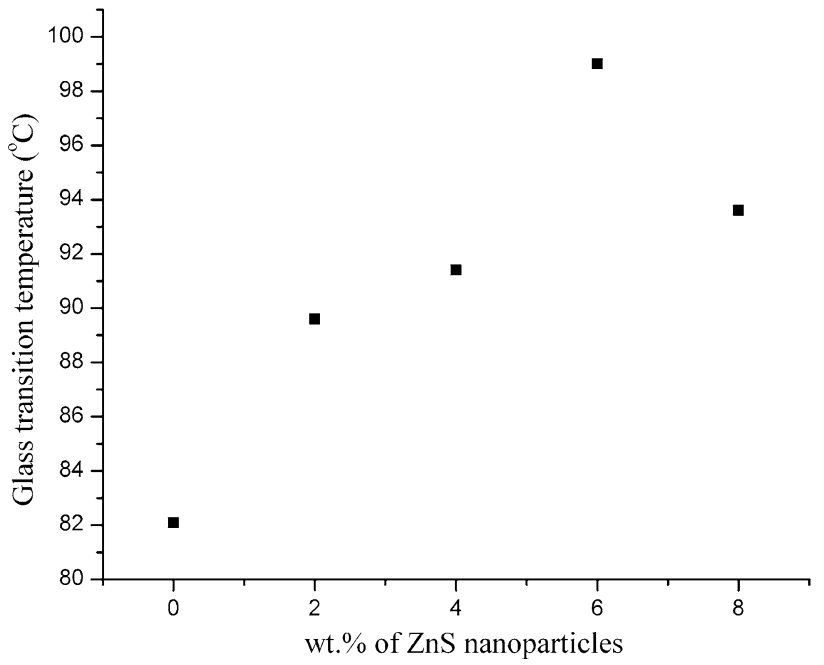

Fig. 6 Composition dependence glass transition temperature

polymer chains straighten out more and more, increasing the corresponding mean free path. This results in minimization of the chain defects and thus the contribution to the corresponding thermal resistance decreases linearly with the rise in temperature and as a result thermal conductivity increases.

Above the glass transition temperature region, scattering by micro-voids (vacant site scattering) contributes to the thermal resistance besides structural scattering. As the temperature increases the polymer passes gradually from glassy to rubbery state. During this transformation 
individual units of polymer, atomic groups and small chain segments undergo intensive thermal motion and large torsional rotations and the sliding of chain segments starts to play a dominant role to control the thermal conductivity above the glass transition temperature. This has two-fold effects on the structure of the system; initially the dominant chain moments create some vacant sites or micro-voids which scatter phonon in the similar way to the point defects (Leed and Millens 1977). With the increase of temperature, the number and size of these micro-voids increase and consequently, the contribution of vacant site scattering to the thermal resistance would increase linearly with temperature. Thus the structure scattering and vacant site scattering are responsible to control the thermal conductivity above the glass transition temperature and hence the thermal conductivity becomes constant (Saxena 2010).

It is also observed from Fig. 5 that the effective thermal conductivity of nanocomposites is higher than that of virgin polymer. This behavior can be explained on the basis of compact structure of composites. When the nanoparticles are introduced into the matrix, they acquire the position of voids and reduce the free volume (voids filled with air) resulting into compact structure of composites, which improves the thermal conduction or thermal conductivity of nanocomposites over the pure PMMA. As, the concentration of $\mathrm{ZnS}$ nanofillers increases to $6 \mathrm{wt} \%$, the free volume further decreases and makes the nanocomposites more compact than the composite with 2 and $4 \mathrm{wt} \%$ of $\mathrm{ZnS}$. This seems to be the optimum compact structure for which the effective thermal conductivity is maximum in the entire studied range of temperature. It is also seen from Fig. 5 that beyond $6 \mathrm{wt} \%$ of $\mathrm{ZnS}$ nanoparticles the effective thermal conductivity decreases in the entire range of temperature. This behavior of thermal conductivity can be explained on the basis of the structural changes occurring in the composite due to the change in dispersion of nanoparticles from uniform to agglomeration, as indicated by the TEM images (Fig. 4).

\section{Conclusions}

The TEM studies reveal that $\mathrm{ZnS}$ nanoparticles embedded in PMMA show the uniform distribution at low filler percentage and particles agglomeration at higher filler percentage. Increment in thermal conductivity of each polymer nanocomposites with the increase of temperature up to glass transition temperature is due to straightening of the chains of polymer. Beyond glass transition temperature of nanocomposite, the thermal conductivity becomes constant due to structure and vacant site scattering of phonons. Besides this, the thermal conductivity of $\mathrm{ZnS} / \mathrm{PMMA}$ nanocomposites increases up to $6 \mathrm{wt} \%$ of $\mathrm{ZnS}$ nanoparticles and beyond this $\mathrm{wt} \%$, it decreases. This is suggestive of the fact that compact structure of nanocomposites and agglomeration of $\mathrm{ZnS}$ nanoparticles, respectively, are responsible for the said variation.

Acknowledgments The authors are thankful to Council of Scientific and Industrial Research (CSIR), New Delhi for providing financial assistance through an Emeritus Scientist scheme to Prof. N.S. Saxena during the course of this work. One of the authors (Sonalika Agarwal) would also be thankful to Dr. Narendra Kumar, (Director, KIET, Ghaziabad) and Professor C. M. Batra (Head, Dept. Applied Sciences, KIET, Ghaziabad) and also like to thank Dr. Mahesh Baboo for his help in various ways.

Open Access This article is distributed under the terms of the Creative Commons Attribution License which permits any use, distribution, and reproduction in any medium, provided the original author(s) and the source are credited.

\section{References}

Agrawal S, Patidar D, Saxena NS (2011) Glass transition temperature and thermal stability of ZnS/PMMA nanocomposites. Phase Transit 84:888-900

Agrawal S, Patidar D, Saxena NS (2013) Effective thermal conductivity of $\mathrm{CdS} / \mathrm{ZnS}$ nanoparticles embedded polystyrene nanocomposites. Heat and Mass Trans 49:947-953

Ash BJ, Schadlen LS, Siegel RW (2002) Glass transition behavior of alumina/polymethylmethacrylate nanocomposites. Mater Lett 55:83-87

Davis LC, Artz BE (1995) Thermal conductivity of metal-matrix composites. J Appl Phys 77:4954-4960

Fokushima H, Drazal LT, Rook BP, Rich MJ (2006) Thermal conductivity of exfoliated graphite nanocomposites. J Therm A9nal Calorim 85:235-238

Garrett KW, Rasenberg HM (1974) The thermal conductivity of epoxy-resin/powder composite materials. J Phys D Appl Phys 7:1247-1258

Godovsky YK (1992) Thermophysical properties of polymers. Springer, New York

Hands D (1999) Thermal properties. In: Brown R (ed) Handbook of polymer testing. Marcel Dekker, NewYork

Leed TCP, Millens W (1977) (TO Gould Inc.) US Patent, No. 834 4046

Perpechoko II (1981) An introduction to polymer physics. Mir, Moscow

Saxena NS (2010) Thermal and mechanical behavior of polymer nanocomposite. J Polym Eng 30:575-586

Saxena NS, Pradeep P, Mathew G, Thomas S, Gustafsson M, Gustafsson SE (1999) Thermal conductivity of styrene butadiene rubber compounds with natural rubber prophylactics waste as filler. Euro Polym J 35:1687-1693

Sun D, Miyatake N, Sue HJ (2007) Transparent PMMA/ZnO nanocomposite films based on colloidal $\mathrm{ZnO}$ quantum dots. Nanotechnology 18:215606-215611

Thangamani R, Chinnaswamy TV, Palanichamy S, Bojja S, Charles AW (2010) Thermal degradation studies on PMMA-HET acid based oligoesters blends. J Therm Anal Calorim 100:651-660

Wang H, Xu P, Zlong W, Shen L, Du Q (2005) Transparent poly(methyl methacrylate)/silica/zirconia nanocomposites with excellent thermal stabilities. Polym Degra Stab 87:319-327

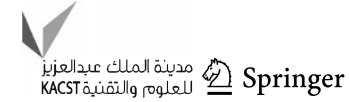


Wong CP, Bollampally RS (1999) Thermal conductivity, elastic modulus, and coefficient of thermal expansion of polymer composites filled with ceramic particles for electronic packaging. J Apply Polym Sci 74:3396-3403
Zhao R, Chen CZ, Li QF, Luo WB (2008) Effects of stress and physical ageing on nonlinear creep behavior of poly(methyl methacrylate). J Cent South Univ Technol 15:582-588 